\title{
La maqueta de Cádiz. De la realidad a la imagen
}

\author{
Luis F. Martínez Montiel, Dpto. de Escultura e Historia de las Artes Plásticas, Universidad de Sevilla
}

La compleja situación política que sufrió Europa durante toda la Edad Moderna, las diversas y diferentes alianzas entre los distintos paises, los enfrentamientos entre ellos y los continuos cambios de estrategias y coaliciones hicieron que el conocimiento preciso de las diversas realidades geográficas de cada una de las naciones fuese considerado una prioridad. Es en ese mundo donde los "relieves de ciudades" toman verdadera carta de naturaleza. Conceptos como los de seguridad de las naciones, nuevas fronteras, herramientas de carácter militar, conocimiento urbano y otros tantos asimilables, están intimamente relacionados con este tipo de creaciones.

Los antecedentes de la singular maqueta de Cádiz habrá que buscarlos en las llevadas a cabo por el Duque de Baviera a mediados del siglo XVI y sobre todo en las levantadas para Luis XIV de Francia. La idea de realizar el modelo de la ciudad de Cádiz se remonta a 1723, cuando a Miguel Marin le es encargado visitar la plaza y levantarla. Sin embargo, en aquel momento no se llevará a cabo y habrá que esperar hasta 1776 para que, con la creación del Gabinete de relieves, se den los primeros pasos en su construcción. Es en ese año cuando se encarga al capitán del Regimiento de la Princesa, el ingeniero Alfonso Jiménez, la creación de las maquetas de Melilla, el Peñón y Alhucemas. La calidad de la realización produjo un efecto inmediato. Será el reconocido arquitecto Francisco Sabatini quien lance sus primeros elogios declarando que ante éstas se sentía del mismo modo que si estuviese en el propio terreno. Tan importante opinión facilitó que por el mismo artífice se llevaran a cabo los relieves de las islas Chafarinas (islas del Rey, del Congreso y de Isabel II). Estos modelos facilitaron la decisión de llevar a cabo el levantamiento sistemático de las principales plazas fuertes de España.

El primer encargo que debería realizar el citado Gabinete, y a la postre el último, sería la plaza de Cádiz con sus fortificaciones. Inicialmente se pensó en llevarla a cabo en Madrid, para lo que el citado Jiménez debía trasladarse con anterioridad a la ciudad, donde deberia delinear plantas y alzados, levantar bocetos, realizar perfiles y llevar a cabo toda una serie de mediciones que le facilitaran después el levantamiento a su regreso a Madrid. Sin embargo, la complejidad de las labores y el mayor coste de los traslados de operarios y materiales hicieron necesario que la maqueta se hiciese in situ. El 26 de abril de 1777, según consta en un extenso documento custodiado en el Archivo General de Simancas, se comenzaba la construcción de la maqueta gaditana.
Las primeras labores le obligaron a realizar un exhaustivo reconocimiento del terreno, tomando gran cantidad de medidas y levantando planos y documentación que fueron la base de su posterior trabajo. A esa labor directa se le deben añadir la búsqueda de un lugar idóneo que permitiese el levantamiento y custodia de la maqueta y la selección de los artesanos que trabajasen en ella. Ninguna de las dos cuestiones resultó fácil pues la ciudad no contaba con edificios capaces de albergarla por su gran tamaño y los artesanos en muchos casos tampoco cumplian los requisitos que se buscaban. Ubicados finalmente en los almacenes interiores del Baluarte de La Candelaria, la obra fue creciendo rápidamente. Sin embargo, las dificultades del proyecto y la minuciosidad, que se pretendia en él, plantearon numerosas dificultades. En no pocos casos, como en el citado documento se cuenta, Jiménez tuvo no sólo que realizar planos y bocetos sino que además necesitó levantar modelos en cera de una gran fidelidad a la realidad para después traspasarlos al relieve.

Los materiales que se emplearon en su construcción, básicamente maderas, fueron buscados por todas las posesiones españolas y en otros lugares donde aun con dificultades las pudieron conseguir. En su construcción se emplearon madera de pino, cedro, boj, ébano, cerezo, naranjo y acebo junto con otras maderas que pudo conseguir a través de los barcos que viajaban desde La Habana o Manila.

Lentamente la maqueta fue creciendo y aunque con algunas dificultades económicas, que quedan pormenorizadamente recogidas en la documentación, finalmente se dieron por concluidas las cincuenta y una partes que la componian, a los veinte meses del comienzo de las labores. El costo de su creación tampoco fue excesivo pues supuso 130.726 reales de vellón a lo que se debía sumar el sueldo del capitán Alfonso Jiménez, que ascendía a 45.378 reales. Además en esa cantidad estaban todos los gastos destinados al transporte en carro desde Cádiz hasta Madrid. Desgraciadamente, con la construcción de ésta finalizó el gran proyecto de levantar las principales plazas fuertes de Andalucia como asi se habia inicialmente propuesto. Se intentó llevar a cabo la de Gibraltar, pero las grandes dificultades que conllevaba eliminaron rápidamente este proyecto así como el de levantar la ciudad de Ceuta, que también quedó finalmente olvidado.

Asimismo y poco a poco el ingeniero Alfonso Jiménez, tras numerosos problemas personales, iba dejando a un lado es- 


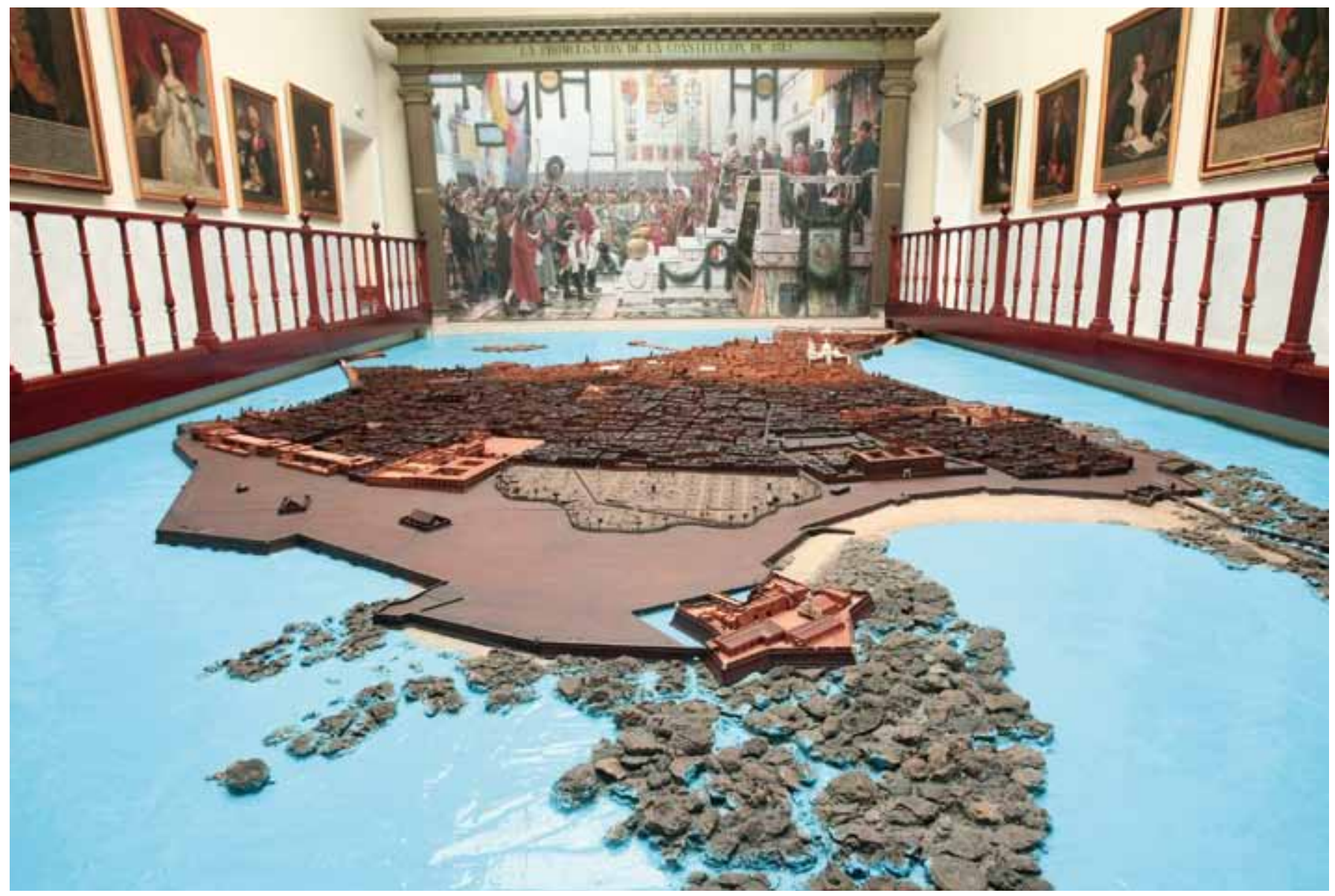

Maqueta de Cádiz. Fuente: Museo de las Cortes de Cádiz

El primer mapa impreso de Andalucía: es el mapa del sevillano Jerónimo de Chaves, publicado en 1579 en Amberes, incluido en el Theatrum orbis terrarum del flamenco Abraham Ortelius. Recoge la demarcación del antiguo obispado de Sevilla, un área de especial importancia en la época

tos grandiosos proyectos y quedando relegado a papeles de segundo orden en los que fue lentamente languideciendo. Su gran obra acabaría siendo la imponente maqueta gaditana que quedaria finalmente expuesta en el Casón del Buen Retiro. Alli permaneció hasta que fue donada al Ayuntamiento de Cádiz. En 1835 ya se habla del lamentable estado de deterioro en que se encontraba en unos almacenes municipales y la necesidad de buscar un lugar digno para ella. Tras su exhibición en varias muestras pasó a instalarse en el entonces Museo Iconográfico de la ciudad (hoy Museo Municipal de las Cortes de Cádiz), donde fue restaurada durante la década de 1950. En la actualidad, reconocida como la pieza emblemática del museo está siendo pacientemente restaurada para devolverle el esplendor que tuvo originariamente.

\section{Bibliografía}

JIMÉNEZ MATA, J.; RUIZ NIETO-GUERRERO, M. P. (1985) Informe. La ciudad de Cádiz y su bajorrelieve de 1777/79. Periferia, 1985, n. 4-5, pp. 145-161 MARTíNEZ MONTIEL, L. F. (1999) La maqueta de Cádiz. Algunos apuntes sobre la construcción y su autor. Laboratorio de Arte, 1999, n. ${ }^{\circ} 12$, pp. 279-290 MORENO CRIADO, R. (1977) La maqueta de Cádiz. Cádiz: Caja de Ahorros de Cádiz, 1977

MUÑOZ CORBALÁN, J. M. (1989) La maqueta de Cádiz (1777-1779). En Actas de las Jornadas sobre la Ingeniería Militar en la Cultura Artística Española. Cádiz, inédito

PEMÁN PEMARTíN, C. (1973) El plano relieve de Cádiz de 1777-1779. En Actas del XXIII Congreso Internacional de Historia del Arte. Granada: Departamento de Historia del Arte de la Universidad, 1973, pp. 651-665

QUIRÓS LINARES, F. (1994) Las colecciones militares de modelos de ciudades españolas, y el Real Gabinete topográfico de Fernando VII. Una aproximación. Eria. Revista de Geografía, 1994, n. 35 , pp. 203-224

EXPEDIENTE 1776- Primeros fechas para la formación del ramo de relieves. Archivo General de Simancas. Guerra Moderna. Legajo 3807 